\title{
13
}

\section{The Right to Science in Practice}

\author{
A Proposed Test in Four Stages \\ Sebastian Porsdam Mann, Yvonne Donders, and Helle Porsdam
}

\subsection{INTRODUCTION}

The human right to enjoy the benefits of the progress of science and its applications (the right to science, or RtS), enshrined in Article 27(2) of the Universal Declaration of Human Rights (UDHR) and Article 15(1)b of the International Covenant on Economic, Social, and Cultural Rights (ICESCR) "adds a legal and moral dimension to a range of fundamental issues, including scientific freedom, funding, and policy, as well as access to data, materials, and knowledge" (Porsdam Mann et al., 2018). Part of the promise is that the RtS, as it becomes more developed, may be used as a legally binding and normatively weighty framework for the assessment of the ethical and human-rights related aspects of science and scientific policy.

This chapter introduces the four-step test, a framework developed as a means to assess whether a policy complies with the obligations imposed by the right to science under international human rights law. In doing so we, like the Committee on Economic, Social and Cultural Rights in its new General Comment (CESCR, 2020), adopt an "internal perspective" for the purposes of this sketch. This means that we have drawn extensively on scholarship, guidance, and interpretation of the ICESCR itself.

Unfortunately, there has not been space here to fully explore the "external perspective," in which the relations between rights across treaties and other human rights instruments are factored into the desiderata that make up our proposed test in four stages. We will explore this in subsequent work. We hope, however, that the sketch presented here will engender fruitful discussion so that it may be made into a useful judicial and policy framework.

\subsection{BACKGROUND}

We take as our points of departure several general approaches to the interpretation of State obligations under international human rights law (Donders, 2011), including 
the provisions laid out in the Vienna Convention on the Law of Treaties (Vienna Convention). ${ }^{1}$ Article 31(1) of the Vienna Convention stipulates that, "[a] treaty shall be interpreted in good faith in accordance with the ordinary meaning to be given to the terms of the treaty in their context and in the light of its object and purpose." This context is defined in Article 31(2) as including general rules of international law as well as further applicable agreements and treaties. More importantly, since there are $\mathrm{few}^{2}$ agreements and treaties between countries with regards to the RtS, Article 31(3) b states that also to be taken into account is "[a]ny subsequent practice in the application of the treaty which establishes the agreement of the parties regarding its interpretation." This includes statements of official treaty bodies, in particular General Comments, which are authoritative interpretations. In our case, the General Comments by the Committee on Economic, Social and Cultural Rights (the Committee) are especially relevant.

As a human right, the RtS places obligations on States which have signed and ratified the ICESCR. According to the tripartite typology (Eide, 1987), an analytical device much used by the UN and human right scholars to interpret the nature of State obligations under human rights law, these obligations can be conceptually stratified into three: the obligation to respect the right, to protect it and, finally, to fulfil it. Paragraph 41 of General Comment No. 25 adopts this language: "States Parties have an obligation to respect, protect and fulfil the [RtS]."

The first refers to the obligation of States not themselves to violate a right or unjustifiably interfere in its enjoyment. The obligation to protect is somewhat more burdensome, requiring that the State must prevent third parties from violating a right. Finally, to fulfil a right, a State must ensure (facilitate and provide) that the various resources, infrastructure, and necessary funding are available to fully realize its enjoyment, also for noncitizens.

As of this writing, 174 countries have signed the ICESCR. Of these, 170 are full States Parties; however, Palau, Comoros, Cuba, and the United States of America have signed but not ratified the Convention. As Cesare Romano points out in his contribution to this volume, the USA is, however, bound by the UDHR ${ }^{3}$ and the American Declaration of the Rights and Duties of Man, the latter of which contains the first instance of the right to science in international law (see Chapter 2).

1 Vienna Convention on the Law of Treaties (adopted May 23, 1969, entered into force January 27, 1980) 1155 UNTS 331.

2 The 2017 UNESCO Recommendation on Science and Scientific Researchers may be seen as an important example.

3 Although the Universal Declaration of Human Rights is a political document, not a legally-binding treaty, it has been viewed by the International Court of Justice, and States, as forming part of customary international law which means it is binding even on those States not a party to it. See, for example, Hurst Hannum. (2018). The Status of the Universal Declaration of Human Rights in National and International Law. GA. J. INT'L E COMP. L., 25, 287-397. 
Moreover, a country which has signed but not ratified the ICESCR is still bound by Article 19 of the Vienna Convention not to act in a way that would defeat the object and purpose of that treaty. In other words, the USA is still bound to respect the RtS. This in contrast to the 170 countries that have signed and ratified the ICESCR, which are in theory bound by all three levels of obligations.

These obligations must, however, compete for scarce resources with other human rights and policy goals. For this reason, the obligations that States are under vis-à-vis the ICESCR are subject to the requirement of progressive realization, laid out in Article 2(1): States must "undertake to take steps, individually and through international assistance and cooperation, especially economic and technical, to the maximum of its available resources, with a view to achieving progressively the full realization of the rights recognized in the present Covenant by all appropriate means, including particularly the adoption of legislative measures."

In its General Comment on Article 2, the Committee has made clear that States are under an obligation to take these progressive steps within a "reasonable, short period of time" and that this obligation "implies not only legislative measures, but also administrative, financial, educational, social and other measures, including judicial remedies" (Donders, 2011). The Committee also states that these obligations are proportional to the resources available to a State, such that the more resources are available, the greater the obligations under the ICESCR.

Paragraph 24 of the General Comment closely follows this phrasing:

States Parties must take steps, to the maximum of their available resources, for the full realization of the $[\mathrm{RtS}]$. While full realization of the right may be achieved progressively, steps towards it must be taken immediately or within a reasonably short period of time. Such steps should be deliberate, concrete and targeted, using all appropriate means, including the adoption of legislative and budgetary measures.

Some obligations, however, are so important that they form an exception to this rule and must be observed immediately, regardless of resources. This includes the obligation under Article 2(2) ICESCR for the rights in that document to be enjoyed without discrimination. Thus, paragraph 25 of the General Comment reminds us that "States Parties are under an immediate obligation to eliminate all forms of discrimination against individuals and groups in their enjoyment of ESCRs."

Finally, both Articles 2(1) and 15(4) ICESCR mention the importance of international cooperation and assistance. In the General Comment on Article 2, the Committee makes clear that, for the purposes of obligations under the ICESCR, "available resources" should be interpreted to include those resources available from international cooperation, and that wealthier countries are under a special obligation to assist the less prosperous (CESCR, 1991). The General Comment on Science, in devoting its sixth section wholly to international cooperation and assistance, stresses the importance of these obligations. 


\section{$13 \cdot 3$ NORMATIVE CONTENT}

The normative content of the RtS has been treated in detail by the General Comment, which draws heavily on the 2017 UNESCO Recommendation on Science and Scientific Research. Section II of the General Comment is titled "Normative Content" and contains several provisions, laid out in paragraphs four to fifteen, which define key terms.

\subsubsection{Science}

Paragraph four of the General Comment quotes the 2017 UNESCO Recommendation's definition of science. Science is:

the enterprise whereby humankind, acting individually or in small or large groups, makes an organized attempt, by means of the objective study of observed phenomena and its validation through sharing of findings and data and through peer review, to discover and master the chain of causalities, relations or interactions; brings together in a coordinated form subsystems of knowledge by means of systematic reflection and conceptualization; and thereby furnishes itself with the opportunity of using, to its own advantage, understanding of the processes and phenomena occurring in nature and society.

As clarified by paragraph six,

science, which encompasses natural and social sciences, [thus] refers both to a process following a certain methodology ("doing science") and to the results of this process (knowledge, applications). Though other forms of knowledge may claim protection and promotion as a cultural right, knowledge should only be considered as science if it is based on critical inquiry and open to falsifiability and testability.

\subsubsection{Scientific Advancement and Scientific Progress}

Paragraph seven defines the terms "scientific advancement" (used in the UDHR) and "scientific progress" (used in the ICESCR): "these expressions emphasize the capacity of science to contribute to the well-being of persons and humankind. Thus, development of science in the service of peace and human rights should be prioritized by States over other uses."

\subsubsection{The Applications of Scientific Progress}

The RtS explicitly recognizes the rights of everyone to enjoy the benefits of science and its applications. The meaning of this latter phrase is defined in paragraph eight of the new General Comment: 
Applications refer to the particular implementation of science to the specific concerns and needs of the population. Applied science also include the technology deriving from scientific knowledge, such as the medical applications, the industrial or agricultural applications, or the information and communication technologies.

\subsubsection{The Benefits}

The General Comment, in paragraph nine, also makes clear that the benefits of scientific progress and its applications extend beyond material gains such as "vaccination, fertilizers, technological instruments and the like." Benefits also refer to

the scientific knowledge and information directly deriving from scientific activity, as science provides benefits through the development and dissemination of the knowledge itself. Finally, benefits refer also to science's role in forming critical and responsible citizens who are able to participate fully in a democratic society.

These definitions will be important resources as we sketch the four-step test framework below.

\subsection{FOUR-STEP TEST}

13.4.1 Step One: Does a Given Policy, Product, or Aspect of Science Constitute a "Benefit of Scientific Progress" or "Its Applications"?

The first step involves determining whether the RtS is applicable to a given situation or issue.

The legal subjectivity of the RtS - the question of who enjoys or is entitled to the right - is every individual human; in other words, all humans are a legal subject of this right. This is a feature of the human rights framework in which the RtS is nested. Secondly, the right applies equally to every human, so it is not the case that some have more or less of a RtS due to, for example, their education or income. These values of inclusion, equality, and universality are fundamental human rights principles, and are included in the Preamble and Article 2 ICESCR.

The scope of the RtS centers on the benefits of scientific progress or its applications. The definitions of these are laid out according to the General Comment in the section above.

Here it should be noted that the RtS grants all individuals the right to share in the benefits of the products of scientific progress, which implies a participatory aspect of the right. As paragraph 54 of the General Comment on Science states, "the principles of transparency and participation are essential to [making] science objective and reliable, and not subject to interests that are not scientific or are against human rights and the welfare of society." 
Although this kind of inclusion is a fundamental human rights principle, the corresponding principle of participation takes on additional nuances in the present context. At one extreme, active participation by the citizenship in a dialogue with science and scientists can "promote public trust and support for sciences," as recognized in paragraphs 54 and 55, and "in particular through a vigorous and informed democratic debate on the production and use of scientific knowledge."

The General Comment acknowledges, however, that the level of participation in science will vary according to the interests and capacities of individuals. Thus, according to paragraph 65 "States parties should ... ensure [the active participation of peasants and other people working in rural areas] in the determination of priorities and the undertaking of research and development, taking into account their experience and respecting their cultures" (emphasis added).

Whereas there are some areas of science in which truly everyone can participate (such as data donation), much of science requires too much specialized knowledge and equipment for even trained scientists to participate in science outside their immediate expertise. There will necessarily be degrees between these extremes.

Thus, the first step in our framework is to ask whether the issue in question meets the definitions laid out in the General Comment and is therefore within the scope of the RtS.

\subsubsection{Step Two: Does the Policy Facilitate or Limit the Enjoyment of the RtS?}

Once it has been determined that an issue is within the scope of the RtS, the next step is categorizing the issue or policy according to whether it fulfills the RtS or meets criteria for legitimate limitations, retrogressive measures, or derogations. It is important to distinguish between these, because although all three involve a lower, or lowering of, the level of enjoyment of the RtS, they have widely different criteria for legitimacy (Donders, 2015).

A derogation is a full or partial elimination of an obligation under international human rights law invoked in exceptional circumstances, such as epidemics, civil unrest, or war. Derogations may be invoked where there is an exceptional threat to the functioning of the State, where a lesser restriction in the form of a limitation does not suffice, where the primary objective of the State in derogating from a right is the fast and full return to a situation in which the enjoyment of human rights can be restored, and where they are used as a last resort (Müller 2009). In addition, not all rights are derogable, although the list of non-derogable rights varies from treaty to treaty.

The ICESCR, unlike the ICCPR, does not contain a derogation clause specifying the circumstances under which a derogation may be legitimately made. Müller (2009) points out that there is not much interpretation by the Committee on Economic, Social and Cultural Rights on the topic of derogations to economic, social and cultural rights, and that their position as to the legal basis of any such 
derogations is unclear. Indeed, the new General Comment does not contain the word "derogation."

The Committee, has, however, in its Statement on Poverty and the ICESCR, stated that certain core minimal obligations are non-derogable: "if a national or international anti-poverty strategy does not reflect this minimum threshold [core obligations], it is inconsistent with the legally binding obligations of a state party" (CESCR, 2001, para. 17). This might be interpreted as implying that some obligations beyond the minimal core are indeed derogable.

A retrogressive measure, on the other hand, is an act which reduces the enjoyment of a human right relative to its previous level of enjoyment, and which thus interferes with the duty of progressive realization of human rights under Article 2(1) ICESCR. "As with all other rights in the Covenant," provides paragraph 24 of the General Comment, "there is a strong presumption that retrogressive measures taken in relation to the RPEBPSA are not permissible." It goes on to list several examples of retrogressive measures:

the removal of programs or policies necessary for the conservation, the development and the diffusion of science; the imposition of barriers to education and information on science; the imposition of barriers to citizen participation in scientific activities, including misinformation, intended to erode citizen understanding and respect for science and scientific research; the adoption of legal and policy changes that reduce the extent of international collaboration on science, etc.

Retrogressive measures may, however, be necessary in exceptional circumstances such as those mentioned above for derogations (where their extent is not such as to require a derogation), but may also be justified by less extreme exigencies, such as severe recessions or natural disasters. The Committee has, in its Statement on the drafting of the Optional Protocol to the ICESCR, given guidelines as to how it will evaluate retrogressive measures in a case-by-case and country-by-country approach according to the following criteria:

(i) The country's level of development;

(ii) The severity of the alleged breach, in particular whether the situation concerned the enjoyment of the minimum core content of the Covenant;

(iii) The country's current economic situation, in particular whether the country was undergoing a period of economic recession;

(iv) The existence of other serious claims on the State party's limited resources; for example, resulting from a recent natural disaster or from recent internal or international armed conflict;

(v) Whether the State party had sought to identify low-cost options; and

(vi) Whether the State party had sought cooperation and assistance or rejected offers of resources from the international community for the purposes of implementing the provisions of the Covenant without sufficient reason. 
To this, the Committee adds, in paragraph 24:

In the exceptional circumstances under which retrogressive measures may be inevitable, States must ensure that such measures are necessary and proportionate. They should remain in place only insofar as they are necessary; they should mitigate inequalities that can grow in times of crisis and ensure that the rights of disadvantaged and marginalized individuals and groups are not disproportionately affected; and in addition guarantee the minimum core obligations.

The fact that retrogressive measures are justified by criteria such as these distinguishes them from limitations. Limitations reflect the fact that the enjoyment of most human rights is not absolute. The human rights of individuals compete with other legitimate goals such as the general welfare and State interests, and individual rights compete with each other for their realization; to reflect the fact that compromises between other projects and other human rights must be made to avoid stalemate, limitations may be imposed.

Of special relevance in the context of the RtS, paragraph 22 of General Comment No. 25 recognizes with regard to limitations that, "[some] limits on the [right] might be necessary, as science and its applications can, in certain contexts, affect [other economic, social and cultural rights]." As we shall see below, there are three elements highlighted in the Committee's understanding: respect for core obligations, proportionality, and the expectation that benefits outweigh burdens.

Policies or issues meeting the criteria for a derogation or retrogressive measure are unlikely to respect the RtS. Such policies will, except in exceptional circumstances, fail to be justified and should not be adopted. However, policies that do not meet the criteria for derogations or retrogressive measures may still infringe on the enjoyment of the RtS to a lesser extent, or two or more policy options may differ in the extent to which they are likely to facilitate enjoyment of the RtS. Whether such limitations are legitimate, and how to choose between competing policy options, is assessed in the next two steps.

\subsubsection{Step Three: Does the Policy Form a Legitimate/Acceptable Limitation on the Enjoyment of the RtS?}

A policy, regulation or law, which is not compatible with the RtS, is one that goes directly against the object and purpose of the RtS (especially its core normative content) or its associated foundational human rights structure. Paragraph 52 of the new General Comment recognizes this in the context of scientific freedom: "core obligations related to the right to participate in and to enjoy the benefits of scientific progress and its applications require States parties to ... remove limitations to the freedom of scientific research that are incompatible with article 4 of the Covenant."

The third step involves evaluation of the options not ruled out by step two as unjustified derogations or retrogressive measures according to the criteria for legitimate limitations contained in Article 4 ICESCR. 
In paragraph 21, the Committee refers to three relevant and important elements of ICESCR Article 4. These are that limitations must be determined by law, they must be compatible with the nature of these rights, and must be enacted solely for the purpose of promoting the general welfare in a democratic society. We comment below on the first and second of these and discuss the third in step four.

To be legitimate, limitations on the RtS must be determined by law. This means that such limitations must, as a minimum, observe the rule of law and be issued through the proper channels. According to the Limburg principles, this means that no limitations may occur unless "provided for by national law of general application which is consistent with the Covenant and is in force at the time the limitation is applied" (paragraph 48); that such laws shall not be "arbitrary or unreasonable or discriminatory" (paragraph 49); that they shall be "clear and accessible to everyone" (paragraph 50); and that adequate "safeguards and effective remedies shall be provided by law against illegal or abusive imposition on application of limitations on economic, social and cultural rights" (paragraph 51). These last safeguards may include vetting by the national judiciary in some national contexts.

For limitations which are proposed but not yet active, the equivalent of this criterion is that such limitations be determinable by law, for example, be of a form that can reasonably be expected to pass through the regular channels of the rule of law.

The requirement that a limitation be compatible with the nature of the rights contained in the ICESCR is an important but somewhat complex aspect of Article 4 .

Firstly, this requires limitations to be compatible with the general and fundamental human rights principles that underlie all of human rights law. Originally set out in the UDHR, these include dignity, the rule of law, equality and nondiscrimination, and universality. Nondiscrimination in particular is mentioned prominently in the ICESCR and UDHR and is considered a core obligation of RtS with respect to science-related policy, both according to existing scholarship and to the new General Comment (paragraphs 26-28; (Donders, 2011)).

Most importantly, this means that everyone enjoys the RtS in equal measure, and thus that ceteris paribus no one's interests can be weightier than their fellow human's. Anything which is contrary to these fundamental principles cannot be compatible with the nature of the rights which are derived from them. Most of these are relatively easy to assess and understand.

Dignity, however, is not so easily defined. It is perhaps the most important, and certainly the most fundamental, human rights principle. At the same time, it is the least well characterized. Philosophers and legal scholars have defined dignity as reflecting, and respecting, the capacity of humans to act as moral agents and to choose for themselves worthwhile projects, goals and expressions of their character in their own life (Beyleveld and Brownsword, 2001). In the human rights system, 
however, the definition of dignity is not based on capacities, but rather on species membership: all humans possess human dignity.

Secondly, as briefly touched upon above, the provision, "compatible with the nature of [ICESCR] rights," has been defined by the Committee in its General Comment No. 25 with regard to the RtS:

As understood by the Committee, this implies that limitations must respect the minimum core obligations of the right, and must be proportionate to the aim pursued, which means that where there are several means reasonably capable of achieving the legitimate aim of the limitation, the one least restrictive to ESCRs must be selected and the burdens imposed on the enjoyment of the RPEBSPA should not outweigh the benefits of the limitation.

This definition is complex in that it is a composite of several more or less easily defined elements. After stressing the respect for minimum core obligations, the Committee goes on to unpack the issue of proportionality into two specifications. The first concerns the selection of the limitation that is the one least restrictive to ESCRs; the second the burdens imposed that should not outweigh the benefits of such a limitation.

In paragraph 51 of General Comment No. 25, the Committee makes clear that "States parties have to implement, as a matter of priority, core obligations." Proposed limitations involving the dereliction of a core obligation are by definition not compatible with the nature of the ESCR rights.

It is extremely significant that the Committee has explicitly declared these to be minimum core obligations. Minimum core obligations are treated differently than other human rights obligations. As explained by Donders (2015):

The CESCR ... has determined that, notwithstanding the concept of progressive realization laid down in Article 2 ICESCR, “ ... a minimum core obligation to ensure the satisfaction of, at the very least, minimum essential levels of each of the rights is incumbent upon every State party" ... “. . . in order for a State party to be able to attribute its failure to meet at least its minimum core obligations to a lack of available resources it must demonstrate that every effort has been made to use all resources that are at its disposition in an effort to satisfy, as a matter of priority, those minimum obligations". In other words, in principle, retrogressive measures may not affect the minimum core of the rights, since the core should be implemented irrespectively of the availability of resources. (emphasis added).

The requirement that any limitations be appropriate and proportionate can be derived from statements by the Human Rights Council and General Comments by the Human Rights Committee on the International Covenant on Civil and Political Rights, and, given their general nature and high importance, it is plausible to argue that they are also applicable in the context of ICESCR rights (Müller, 2009). As we saw, the understanding of 'proportionate' offered by the new General Comment in paragraph 22 encompasses two things: choosing the option least 
restrictive to other economic, social and cultural rights and only imposing burdens that do not outweigh the benefits of such a limitation.

Similarly, General Comment No. 27 on the ICCPR, paragraph 14, states that any limitations must be appropriate to achieving the suggested aim, and must be the least restrictive of the possible options. In the context of the ICESCR, the only legitimate aim of limitations is the general welfare. The requirement of proportionality here serves as a constraint on the choice of a limitation. Out of the set of possible limitations, only that limitation may be chosen which is appropriate for the aim and the least restrictive (on its impact on other human rights).

In practice this will mean that the stronger and more pressing a social need is - in terms of, for example, furthering the general welfare - the more likely it is that a given human right may be limited. Conversely, those rights that are arguably less important for the general welfare require less of a pressing social need to be legitimately limited.

\subsubsection{Step Four: Which is the Best Remaining Option for Promoting the General Welfare in a Democratic Society?}

Finally, once a list of options consistent with the requirements in the preceding three steps has been drawn up, the fourth step provides a few additional tools to narrow down the set of acceptable choices.

According to the final limitation criteria of ICESCR Article 4, "the State may subject such rights [to limitations] ... solely for the purpose of promoting the general welfare in a democratic society." Importantly, it is not just the welfare in a society that is mentioned, but the general welfare. This reflects the human rights principle of inclusiveness and the premise, common to many consequentialist normative theories, that the preferences, interests and welfare of an individual is of the highest importance, but no more so for any one individual than for another.

It is worth stressing this point because it has so many important consequences. First, it makes it much harder to justify a limitation on the RtS which would benefit only a select group of individuals, rather than everyone in the society. Second, and related, this provision forces policymakers and policy evaluators to include all of a society's individual interests in their deliberations before issuing policy. This shift in perspective is likely to be a great boon in itself. It is also likely to increase public confidence in policy.

The "general welfare" is not defined in any greater detail. However, the requirement that any limitations be "solely" for the purpose of the general welfare may be interpreted to imply that limitations cannot be imposed for reasons of public order, public morality, national security, and so on. This essentially leaves only the social and economic wellbeing and happiness of each individual as a legitimate basis for limitations (Müller, 2009). It could however also be argued that public order, public morality, and national security serve the general welfare and are thereby included in 
this concept. Exceptions may also arise due to the close link between the RtS and other human rights that may be limited for some of the aforementioned reasons, such as freedom of expression and freedom of association (Donders, 2015). Moreover, restrictions due to fundamental human rights principles such as dignity and the interdependence of human rights still apply; legitimate limitations must meet all of these standards.

One concrete example where the human rights principle of inclusiveness comes into play is intellectual property (IP). Rights of authors and inventors are important to help assure the public "of the credibility of their claims of innovation," as well as offering "assurance to the public of the authenticity of the works presented to it," wrote Richard Pierre Claude, one of the earliest and most astute commentators on the RtS (Claude, 2002, p. 52). Should these rights clash with people's right to science and culture, however, "the burden of demonstrating priority lies with property rights claimants" (Claude, 2002, p. 53). From a human rights-based perspective, there exists a presumption against property rights because "the use of scientific achievements should promote the fullest realization of human rights without discrimination, including that which follows from the advantages enjoyed by those asserting property rights" (Claude 2002, p. 53).

This radically different baseline assumption, which puts the effects of scientific advances on individuals, rather than the inventor, at the center of analysis, is one of the most important features of the RtS framework. Under it, the default is that everyone should be able to benefit from scientific advances, and only if certain, welldescribed conditions are met, may this presumption in favor of individual access rights be limited. Similarly, the starting point for any conversation concerning the intersection between science and society based on the RtS must be its effects on all citizens equally, and not only those able to pay or otherwise to advance their interests.

That this is necessary is seen by simple statistics such as the 10/90 gap, whose name derives from the fact that less than 10 percent of the worlds medical expenditures are spent on the diseases and conditions which make up 90 percent of the disease burden. Typically this is because the majority of the disease burden is in countries less able to pay for medications; roughly a third of all deaths occur from diseases where a cure or prevention is already known, but is not undertaken or provided for reasons related to resources (Hesketh, 2005): Thus, "[the] issue, however, is not the unavailability of medicines in the world market. The problem in their view is that the poor are unable to access these medicines largely because of poverty, inadequate health infrastructure, and overbearing governments. These barriers need to be removed to make the drugs available to poor people" (Vidyasagar, 2006).

In contrast, access to medicines as a benefit of scientific progress would be the default option under the RtS. The point is that everybody has such a right unless clear, pre-defined criteria are met. 
The inclusion of the qualifier, "in a democratic society", was, during the drafting process, considered to be of "vital importance ... since in its absence ... [the limitation clause] might very well serve the ends of dictatorship" (quoted in Müller, 2009). One way this might happen would be for an authoritarian or other nonrepresentative government to define the general welfare in a way that does not correspond to the aggregate welfare of each individual in society, for example by declaring the welfare of some class of political opponents to be irrelevant, or by focusing on elements of welfare that only benefit some rather than, or at the expense of, others, such as reductions in the maximal income tax brackets, or subsidies for farms or churches. Thus what really matters here is not necessarily that the government form be a pure democracy, but rather that it be a kind of governance structure that truly and equally values the interests of each member of society, rather than the ruling or some other class.

Of relevance here is also Section III: Elements of the right and its limitations of the General Comment, in its Section A, which lays out the elements of the right using the commonly utilized four-A (here AAQA) scheme. Paragraph 19, which defines acceptable science, includes a maximizing principle:

Acceptability implies also that scientific research has to incorporate ethical standards ... Some of these standards are: benefits to research participants and other affected individuals should be maximized and any possible harm minimized with reasonable protections and safeguards [emphasis added].

It can be argued that a maximizing principle is implied generally. Just as proportionality means that the least restrictive option should be chosen, so the importance of the general welfare - the only aim for which limitations may be set - implies that the option most likely to provide the most overall general welfare should be chosen. We submit on our own authority that, ceteris paribus, the operative word must be preferred over the weaker should.

Thus, step four asks which of the policy options that have cleared steps one through three, as well as being appropriate, proportionate, and necessary in a democratic society, are likely to add to the general welfare of society, and requires that we choose the one out of these most likely to lead to the greatest increase in general welfare.

\section{$13 \cdot 5$ CONCLUDING REMARKS}

One section of the new General Comment is dedicated to the interdependence of the RtS with other rights. Thus, paragraph 63 acknowledges that, "the REBSP is a human right with an intrinsic value, but it also has an instrumental value, as it constitutes an essential tool for the realization of other ESCRs, in particular for the right to food and the right to health."

In a systematic review conducted of the literature on the RtS, the most commonly stressed themes found were access and the connection to other human rights, with 
other highly cited themes including intellectual property protection, participation in science, and dual use (Porsdam Mann et al., 2018; Porsdam Mann, Donders, and Porsdam, 2020). Thus, it was acknowledged that science is important for the fulfilment of other human rights duties, but also that it has value of its own.

The RtS has wide applicability across themes at the intersection between science, society and the individual. Part of its promise lies in its universal nature: since the $\mathrm{RtS}$ is a human right, everyone is, in theory, equally entitled to enjoy it. The idea is that, barring good reasons to the contrary, everyone should be able to enjoy access to the benefits of the progress of science and its applications. By comparison, the standard framework for regulating access to scientific materials and output today is based on intellectual property protection, which is exclusionary in nature. Here, the idea is that, barring good reasons to the contrary, no one should be allowed access to the benefits of scientific progress unless they are willing and able to pay.

Our aim has been to provide a sketch of a framework for the assessment of policies according to their compliancy or otherwise with the obligations imposed by the RtS. One of the strengths of our model is that it has been developed using only pre-existing concepts and instruments, which should be largely uncontroversial, and should facilitate the evaluation of human rights implications by those familiar with these tools.

In the first step, general definitions are brought to bear to determine whether an issue or policy proposal falls within the scope of the RtS. The second step involves figuring out whether any of a set of proposals fulfils the RtS, and if it does not, whether the options are best classified as derogations, retrogressive measures, or limitations. In step three, commonly accepted human rights instruments and concepts are used to determine the legitimacy of proposed policy options. The fourth and final step then simply requires the choice of the best possible remaining option.

A policy option that makes it all the way through the four-step test fulfils the following criteria: it is enacted according to the rule of law; and it is the option which produces the greatest amount of general welfare in a democratic society out of the set of options which are based on science, compatible with the nature of economic, social and cultural rights, respect fundamental human rights principles, and are balanced according to their impact on the enjoyment of all human rights. Beholden to the general and individual interest, it is our contention that any such outcomes are likely to be superior to the criteria according to which current science policy is determined.

Our hope is that by bringing together different schemes, including the General Comment No. 25 and academic reflections, this sketch has contributed toward building a useable framework that may help activate the RtS in practice.

\section{REFERENCES}

Beyleveld, D., and Brownsword, R. (2001). Human Dignity in Bioethics and Biolaw. Oxford; New York: Oxford University Press. 
CESCR. (1991). CESCR General Comment No. 3: The Nature of States Parties' Obligations (Art. 2, Para. 1, of the Covenant). (UN Doc E/1991/23).

CESCR. (2001). Statement on Poverty and the ICESCR. (E/C.12/2001/10). Retrieved from https://digitallibrary.un.org/record/452397?ln=en.

CESCR. (2020). General comment No. 25 on science and economic, social and cultural rights (article 15 (1) (b), (2), (3) and (4) of the International Covenant on Economic, Social and Cultural Rights). (UN Doc E/C.12/GC/25).

Claude, R. P. (2002). Science in the Service of Human Rights. Philadelphia: University of Pennsylvania Press.

Donders, Y. (2011). The Right to Enjoy the Benefits of Scientific Progress: In Search of State Obligations in Relation to Health. Medicine, Health Care, and Philosophy, 14(4), 371-381.

Donders, Y. (2015). Balancing Interests: Limitations to the Right to Enjoy the Benefits of Scientific Progress and Its Applications. European Journal of Human Rights, 4, 486-503.

Eide, A. (1987). The Right to Adequate Food as a Human Right. (E/CN.4/Sub.2/1987/23). Retrieved from https://digitallibrary.un.org/record/139080?ln=en.

Hesketh, T. (2005). The 10/90 Report on Health Research 2003-2004 Global Forum for Health Research. Transactions of The Royal Society of Tropical Medicine and Hygiene, $99(8), 638-638$.

Müller,A., "Limitations to and Derogations from Economic, Social and Cultural Rights," Human Rights Law Review, Volume 9, Issue 4, 2009, Pages 557-601.

Porsdam Mann, S., Donders, Y., Mitchell, C., Bradley, V. J., Chou, M. F., Mann, M., Porsdam, H. (2018). Opinion: Advocating for Science Progress As a Human Right. Proceedings of the National Academy of Sciences, 115(43), 10820-10823.

Porsdam Mann, S., Donders, Y., and Porsdam, H. (2020). Sleeping Beauty: The Right to Science As a Global Ethical Discourse. Human Rights Quarterly, 42.

Vidyasagar, D. (2006). Global Notes: The 10/90 Gap Disparities in Global Health Research. Journal of Perinatology, 26(1), 55-56. 